CLINICAL STUDY

\title{
Retinol-binding protein 4 levels are elevated in polycystic ovary syndrome women with obesity and impaired glucose metabolism
}

\author{
Susanne Hahn, Manuel Backhaus ${ }^{1}$, Martina Broecker-Preuss ${ }^{1,2}$, Susanne Tan ${ }^{1}$, Tiina Dietz ${ }^{1}$, Rainer Kimmig ${ }^{3}$, \\ Markus Schmidt $^{3}$, Klaus Mann ${ }^{1}$ and Onno E Janssen ${ }^{4}$ \\ Endokrinologikum Ruhr, Center for Endocrine and Metabolic Diseases, Alter Markt 4, 44866 Bochum, Germany, ${ }^{1}$ Division of Endocrinology, Department \\ of Medicine, ${ }^{2}$ Division of Clinical Chemistry and Laboratory Medicine and ${ }^{3}$ Department of Obstetrics and Gynecology, University Hospital of Essen Medical \\ School, 45122 Essen, Germany and ${ }^{4}$ Division of Endocrinology, Metabolism and Molecular Medicine, Feinberg School of Medicine, Northwestern \\ University, 60611 Chicago, Illinois, USA
}

(Correspondence should be addressed to S Hahn; Email: mail@susannehahn.com)

\begin{abstract}
Objective: Insulin resistance and obesity are common features of the polycystic ovary syndrome (PCOS). Retinol-binding protein 4 (RBP4), a new fat-derived adipokine, has been described to be elevated in obesity and type 2 diabetes. The aim of the present study was to investigate whether serum RBP 4 levels are correlated with metabolic parameters, indices of insulin resistance, and endocrine variables in German PCOS women.

Design: We assessed the correlation between metabolic and endocrine parameters with RBP4 levels in 200 PCOS patients and 64 healthy controls.

Methods: Serum RBP4 was measured by enzyme-linked immunosorbent assay (Immundiagnostik AG, Bensheim, Germany). In addition, anthropometric variables, clinical signs of hyperandrogenism, and body fat were evaluated, and a glucose tolerance test was performed to assess parameters of insulin resistance and glucose metabolism.

Results: Taking the entire PCOS cohort, RBP4 levels were positively correlated with body mass index (BMI), body fat, waist circumference, fasting glucose, and area under the curve for glucose (all $P<0.05)$, but not with indices of insulin resistance. On the other hand, PCOS women with impaired glucose metabolism had higher RBP4 levels than PCOS women with normal glucose metabolism (median 30.6, range 23.3-73.9 versus median 26.3, range 6.4-61.4, $P<0.05$ ). Furthermore, no differences were found in RBP4 levels between lean PCOS women and BMI-matched healthy controls. Conclusion: In German PCOS women, serum RBP4 levels are associated with obesity and parameters of glucose metabolism but not with PCOS per se.
\end{abstract}

European Journal of Endocrinology 157 201-207

\section{Introduction}

Polycystic ovary syndrome (PCOS) is among the most common endocrine disorders in fertile women. In addition to chronic anovulation and hyperandrogenism, obesity is a common feature of women with PCOS in different ethnic cohorts, affecting about half of the entire PCOS population $(1,2)$. It has been established that the association of PCOS with insulin resistance and alterations in $\beta$-cell function (3) constitutes a primary cause for the predisposition of patients to develop a metabolic syndrome, an impaired glucose tolerance (IGT) (4), or overt type 2 diabetes mellitus (T2DM) (5). Moreover, the onset of glucose intolerance in PCOS women has been reported to occur at an earlier age (i.e. approximately by the third to fourth decade of life) than in the normal population (6). The pathogenesis of insulin resistance and T2DM in PCOS women is likely to be multifactorial. Insulin resistance increases with increasing body mass index (BMI) and waist circumference as a clinical sign of central obesity (7). Whilst a family history of obesity, insulin resistance, and T2DM appears to be more prevalent in affected women (8), it is unclear whether this association is due to environmental or inherited factors, thus implicating a genetic background. Several T2DM candidate genes, including those for insulin, the insulin receptor, and insulin receptor substrates, have been investigated in this context, indicating evidence for a genetic contribution to PCOS susceptibility $(9,10)$.

Adipose tissue has been established as a major endocrine organ. Through the release of peptides such as adiponectin $(11,12)$, resistin, and leptin, it is involved in the pathogenesis of several metabolic disorders. Through the study of adipocyte-specific glucose transporter 4 (Glut 4) knockout mice, retinol-binding protein 
4 (RBP4) has been identified as another adipocytederived molecule that contributes to obesity and T2DM in humans (13). Yang and co-workers found that serum RBP4 levels were increased about 1.9-fold in obese nondiabetic and obese diabetic subjects when compared with lean controls. Moreover, their study documented a decrease in RBP4 levels in adipose Glut $4^{-1-}$ mice after rosiglitazone treatment. Similar results have been reported in human studies. In lean HIV-positive subjects, Haider and colleagues found a significant decrease in $\mathrm{RBP} 4$ levels after treatment with $8 \mathrm{mg}$ /day rosiglitazone for 6 months (14). RBP4 concentrations were also shown to be markedly higher in morbidly obese patients than in lean controls (15). In this study cohort, weight reduction after gastric banding decreased RBP4 levels significantly, and multiple linear regression analysis revealed that changes in BMI were the best independent predictor for changes in RBP4. In Mongolians, a functional single nucleotide polymorphism (SNP) in the RBP4 gene was found to be associated with type 2 diabetes (16). Data from Craig et al. (17) showed that a haplotype comprising all common SNPs in the RBP4 gene may increase diabetes susceptibility in Caucasians. There is increasing evidence supporting the hypothesis that RBP4 is an adipocyte-derived factor that may contribute to the pathogenesis of T2DM by regulating systemic glucose metabolism.

The aim of the present study was to investigate whether serum RBP4 levels are correlated with metabolic parameters, indices of insulin resistance, and endocrine variables in German PCOS women.

\section{Subjects and methods}

\section{Study population}

PCOS patients PCOS patients $(n=200)$ seeking medical advice for cycle abnormalities, hirsutism, obesity, or infertility were prospectively recruited from the outpatient clinics of the Division of Endocrinology, Department of Medicine and the Department of Obstetrics and Gynaecology at the University of Duisburg-Essen. Based on the criteria derived from the 1990 National Institutes of Health (NIH) conference, diagnosis of PCOS was established when either oligomenorrhea (cycles lasting longer than 35 days) or amenorrhea (less than two menstrual cycles in the past 6 months) and either clinical signs of hyperandrogenism (hirsutism or obvious acne or alopecia) and/or an elevated total testosterone (testosterone normal range $<2.0 \mathrm{nmol} / \mathrm{l}$ ), in combination with an elevated free androgen index (FAI; FAI normal range <4.97) were found, and other pituitary, adrenal or ovarian diseases could be excluded by history, physical examination and laboratory tests. To this end, levels of luteinizing hormone (LH), follicle-stimulating hormone (FSH), estradiol, prolactin, cortisol, adrenocorticotropin (ACTH), thyroid stimulating hormone (TSH), insulinlike growth factor (IGF), and androstenedione were determined in all study subjects. In all women with 17-hydroxyprogesterone levels below $10 \mathrm{ng} / \mathrm{ml}$, ACTHstimulated 17-hydroxyprogesterone was also measured. When either the basal or the stimulated value was $>10 \mathrm{ng} / \mathrm{ml}$, a genetic analysis (21-hydroxylase deficiency) was performed, and when positive, women were excluded from this study. Hirsutism was routinely graded by two physicians independently using the common modified Ferriman-Gallwey score (FG). FG scores never differed by more than 2, and when not identical, were re-evaluated by a third physician and the median value used. Hirsutism was diagnosed when a score above 5 was found. Androgenetic alopecia was defined as diffuse hair loss over the mid-scalp. The degrees of thinning were divided into three categories, the Ludwig scores 1-3 (18). By fulfilling the NIH criteria, all women also fulfilled the 2003 Rotterdam criteria (19). The Rotterdam criteria define PCOS, after the exclusion of related disorders, by two of the following three features: 1) oligo- or anovulation, 2) clinical and/or biochemical signs of hyperandrogenism, or 3) polycystic ovaries (PCO). PCO were defined by the ESHRE/ASRM criteria when either a volume of at least $10 \mathrm{ml}$ or more than 12 follicles (diameter between 2 and $9 \mathrm{~mm}$ ) were found in at least one ovary.

PCOS subjects were taking no medication known to affect either carbohydrate metabolism or endocrine parameters for at least 3 months before entering the study. All study participants were of Caucasian origin and gave written informed consent before entering the study.

Control population Women in the control group ( $n=64$, age- and BMI- matched to the lean PCOS subgroup) were recruited from a health screening program for employees instituted at the University Hospital of Essen Medical School and by public advertisement. All NIH-PCOS criteria (oligo- or anovulation and clinical as well as biochemical signs of hyperandrogenism) were excluded in controls before entering the study. Thus, PCOS was also excluded by the 2003 Rotterdam criteria. Other exclusionary criteria for controls were any known medical condition, except allergy medications and occasional pain medications.

\section{Data collection}

In PCOS subjects and control women, clinical parameters were assessed by physical examination, including the degree of hirsutism by evaluating the FG, 
the presence of acne or alopecia, and anthropometric measurements including body weight in $\mathrm{kg}$ and waist circumference $(\mathrm{W})$ in $\mathrm{cm}$. The BMI was calculated as weight $/(\text { height })^{2}\left(\mathrm{~kg} / \mathrm{m}^{2}\right)$ and body fat was assessed using whole body scans by dual energy X-ray absorptiometry (DEXA, Lunar, Madison, WI, USA). The coefficient of variance was determined by repeated measurements and was $2.2 \%$ for total fat mass. Sitting blood pressure was measured twice after a 15 min rest from the right arm using a standard sphygmomanometer, while the appearance of the first sound (Korotkoff sound, phase I) was used to define systolic blood pressure and the disappearance of sound (phase $\mathrm{V}$ ) defined diastolic blood pressure. We used the average of the two measurements for statistical analysis. In addition, medical and family histories (PCOS, T2DM) were obtained by personal interview. PCOS women were instructed to document the frequency and length of menstrual bleedings. After an overnight fast of $12 \mathrm{~h}$, a $75 \mathrm{~g}$ oral glucose tolerance test (OGTT) with determination of glucose and insulin levels at baseline and at 30, 60, 90, 120, and $180 \mathrm{~min}$, was performed. Insulin resistance was defined by the HOMA model (20) and insulin sensitivity by evaluating the QUICKI (21). In addition, whole-body insulin sensitivity (ISI Matsuda) (22), which combines hepatic and peripheral insulin sensitivity, was calculated by the formula:

$10000 / \sqrt{ }\left(\mathrm{G}_{\text {fasting }} \times \mathrm{I}_{\text {fasting }}\right)\left(\mathrm{G}_{\text {OGTT }} \times \mathrm{I}_{\text {OGTT }}\right)$

where $\mathrm{G}=$ glucose, $\mathrm{I}=$ insulin; ogTt denotes mean during OGTT.

Hyperinsulinemia was determined by calculating the area under the insulin response curve (AUC-I) and $\beta$-cell function by HOMA-B (20). Impaired fasting glucose (IFG), IGT, and type 2 diabetes were defined by the classification from the German Diabetes Association, which is identical to that of the American Diabetes Association. Prior to the OGTT (between 0800 and $0900 \mathrm{~h}$ ), blood samples were drawn for the measurement of all other metabolic (RBP4, total cholesterol, high-density lipoprotein (HDL) cholesterol, low-density lipoprotein (LDL) cholesterol, triglycerides (TG), and glycosylated fraction of hemoglobin-A1c (HbAlc)) and endocrine (LH, FSH, estradiol, testosterone, sex hormone-binding globulin (SHBG), prolactin, cortisol, ACTH, TSH, IGF, androstenedione, and 17-hydroxyprogesterone) parameters. The presence of PCO, as defined by the ESHRE/ASRM criteria (19), was documented by transvaginal ultrasound in all PCOS women. The FAI was calculated as testosterone (nmol/l)/SHBG $(\mathrm{nmol} / \mathrm{l}) \times 100$. In oligomenorrhoic women, all laboratory determinations and clinical evaluations were performed in the follicular phase of the cycle, while amenorrhoic women were tested independent of the time point of their last menses.

\section{Biochemical assays}

Automated chemiluminescence immunoassay systems were used for the determination of LH, FSH, estradiol, testosterone, prolactin, cortisol, TSH, total cholesterol (CHOL), HDL cholesterol, LDL cholesterol, TG, and blood glucose (ADVIA 1650, Bayer Diagnostics), androstenedione, ACTH, insulin, and SHBG (IMMULITE 2000, DPC Biermann, Bad Nauheim, Germany), and IGF-1 (Nichols Advantage, Nichols Institute Diagnostics, Bad Vilbel, Germany). The glycosylated fraction of HbA1c was determined by an automated HPLC method on an A1c 2.2 glycohemoglobin analyser (TOSOH-Eurogenetics, Cologne, Germany). Intra-assay variation was $<5 \%$ and inter-assay variation was $<8 \%$ for all measured parameters. 17-hydroxyprogesterone was measured by the Biosource 17-alpha-OH-RIA-CT kit (Biosource International, Camarillo, CA, USA; analytical sensitivity $0.02 \mathrm{ng} / \mathrm{ml}$ ) provided by IBL Hamburg (IBL, Gesellschaft für Immunchemie und Immunbiologie, Hamburg, Germany). The intra- and inter-assay coefficients of variation were 5.6 and $7.2 \%$ respectively. RBP4 was measured using an enzyme-linked immunosorbent assay (Immundiagnostik AG, Bensheim, Germany). The intra- and inter-assay coefficients of variation were 5.0 and $9.8 \%$ respectively.

\section{Statistical analysis}

Data are presented as mean \pm s.D. and as median and range, or as number and percentage of affected women. Wherever continuous variables were compared at baseline, $t$-test (in case of two groups) or ANOVA (in case of more than two groups) was applied. For not normally distributed variables, Wilcoxon rank sum test (in case of two groups) or Kruskal-Wallis test (in case of more than two groups) was performed. For correlation analysis, Spearman correlation coefficient was used. Statistical analysis and box plot graphs were computed using GraphPad Prism 4 (GraphPad Software Inc., San Diego, CA, USA). $P$ values $<0.05$ were considered significant.

\section{Results}

The majority of PCOS women were oligomenorrhoic $(n=141,70.5 \%)$. Regarding clinical signs of hyperandrogenism, $49 \%$ of PCOS subjects presented with acne, $22 \%$ with mild alopecia (Ludwig Score $<2$ ), and 62\% with hirsutism. In our German PCOS cohort, a mean FG score of 8 was found. PCO, defined by the ESHRE/ASRM criteria, were diagnosed in $78.5 \%$ of PCOS patients. Out of 200 PCOS subjects, 58 (29\%) were lean, 33 (16.5\%) were overweight with a BMI between 25 and $29.9 \mathrm{~kg} / \mathrm{m}^{2}$, and $109(54.5 \%)$ were obese. In the obese group, 41 women had a BMI between 30.0 and $34.9 \mathrm{~kg} / \mathrm{m}^{2}, 31$ had a BMI between 35.0 and $39.0 \mathrm{~kg} / \mathrm{m}^{2}$, and 37 had a BMI 
$>40 \mathrm{~kg} / \mathrm{m}^{2}$. Of the entire PCOS cohort, 5 women presented with IFG, 10 had IGT, and 11 women were diagnosed with overt T2DM. As all subjects with previous history of T2DM or antidiabetic medication were excluded from this study, all findings of pathological glucose metabolism were de novo diagnoses based on the OGTT results. A comparison of PCOS women with normal glucose metabolism with PCOS women with impaired glucose metabolism (IFG, IGT, and T2DM) revealed higher serum RBP4 levels in the latter group (median 26.3, range 6.4-61.4, mean 28.0 \pm 9.9 versus median 30.6, range 23.3-73.9, mean 35.8 \pm 13.6 ; Fig. 1 ). In the entire PCOS cohort, a positive family history of T2DM was found in 107 women $(53.5 \%)$. Of those 107 patients, 38 PCOS patients had diabetic mothers/ \pm grandparents or fathers/ \pm grandparents $(35.5 \%$ ), and 69 women had only affected grandparents (64.5\%). Interestingly, no differences were found in RBP4 levels between PCOS women with or without type 2 diabetic relatives (Fig. 2).

As expected, metabolic variables and parameters of insulin resistance differed significantly between lean, overweight, and obese PCOS patients (Table 1). In addition, significantly different RPB4 levels were observed between the groups. RBP4 levels correlated with parameters of glucose metabolism but not with variables of insulin resistance (Table 2). However, RBP4 concentrations were not correlated with biochemical or clinical endocrine parameters (data not shown).

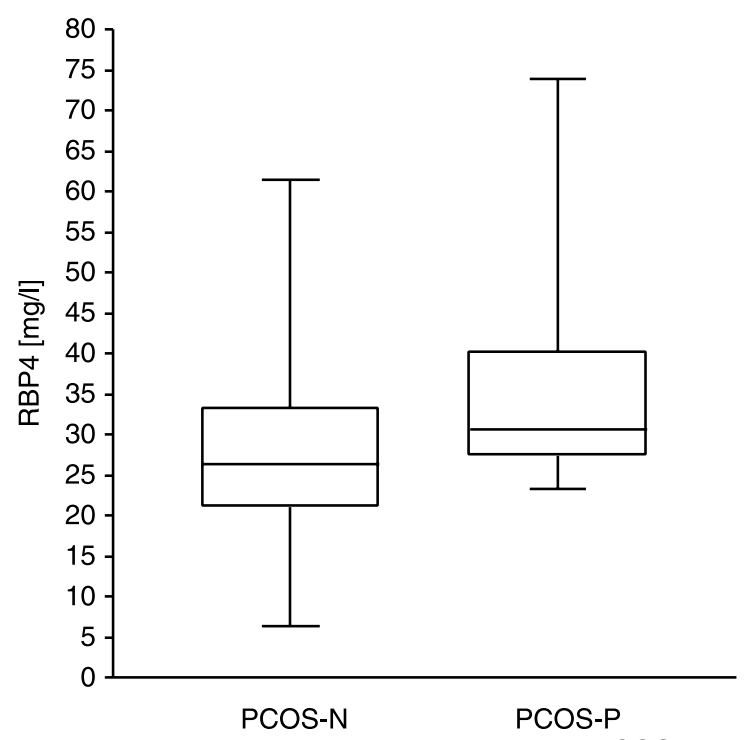

Figure 1 Retinol-binding protein 4 levels in PCOS women depending on glucose metabolism. Retinol-binding protein 4 levels were measured in PCOS patients with normal glucose tolerance (PCOS-N, $n=174$ ) and impaired glucose metabolism (PCOS-P: impaired fasting glucose, impaired glucose tolerance, and overt type 2 diabetes mellitus, $n=26)$. Differences between the groups were statistically significant $(P=0.028)$. Data are shown by box and whiskers graph. The box extends from the 25th to the 75th percentile, with a line at the median indicating the 50th percentile. The whiskers represent the ranges extending from the lowest to the highest value.

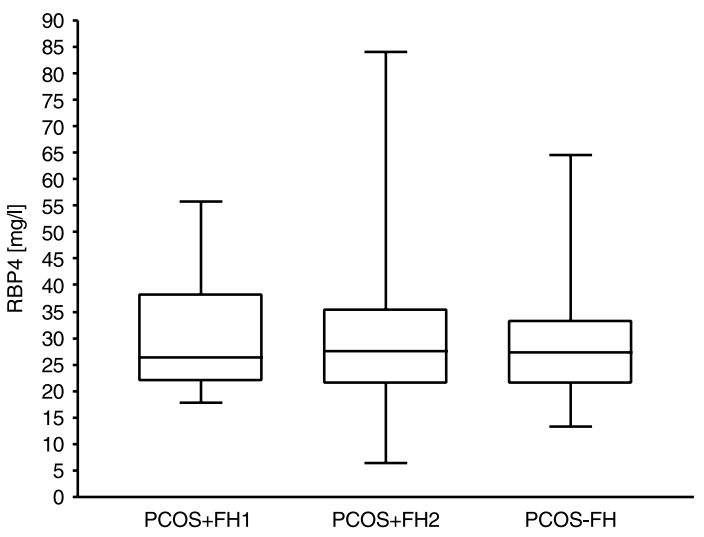

Figure 2 Retinol-binding protein 4 levels in PCOS women depending on family history of type 2 diabetes. Retinol-binding protein 4 levels were measured in PCOS patients with a positive family history of type 2 diabetes mellitus (PCOS $+\mathrm{FH} 1$ : mothers/ \pm grandparents or fathers/ \pm grandparents, $n=38$; PCOS $+\mathrm{FH} 2$ : only grandparents affected, $n=69$ ) and without a positive family history of type 2 diabetes (PCOS-FH, $n=93$ ). Differences between the groups were not statistically significant $(P=0.47)$. Data are shown by box and whiskers graph. The box extends from the 25th to the 75th percentile, with a line at the median indicating the 50th percentile. The whiskers represent the ranges extending from the lowest to the highest value.

To examine the effect of PCOS per se on RBP4 levels, we compared lean PCOS women with age- and BMImatched healthy controls. As expected, clinical and biochemical parameters of hyperandrogenism differed significantly between the groups (Table 3). No differences were found in RBP4 levels between PCOS women and controls, thus implicating that RBP4 levels are not influenced by hyperandrogenism per se. However, PCOS women and controls differed significantly in HDL levels, TG, and HbA1c.

\section{Discussion}

In this German PCOS cohort, more than half of the patients were overweight or obese, which is comparable with other PCOS populations $(5,23)$. Women with PCOS are known to be at an increased risk for the development of IGT and T2DM, which is thought to be a direct consequence of the high prevalence of obesity and insulin resistance. Furthermore, in PCOS women with normal glucose tolerance, a conversion rate to an IGT of $16 \%$ per year has been reported (24). In addition to obesity and a positive family history of type 2 diabetes, other risk factors are being discussed to contribute to the high prevalence of insulin resistance and abnormal glucose metabolism in PCOS women. Low adiponectin, high leptin (25), and low ghrelin (26) levels were shown to be associated with insulin resistance and BMI in PCOS patients. RBP4 levels were associated with obesity, insulin resistance, and type 2 diabetes not only in mouse models of obesity and insulin resistance, but also in humans with these conditions. Hence, increased 
Table 1 Metabolic characteristics of women with polycystic ovary syndrome (PCOS) dependent on body mass index (BMI).

\begin{tabular}{|c|c|c|c|c|}
\hline & PCOS lean $(n=58)$ & $\begin{array}{l}\text { PCOS overweight } \\
(n=33)\end{array}$ & PCOS obese $(n=109)$ & $\boldsymbol{P}$ \\
\hline Age (years) & $\begin{array}{l}25.9 \pm 5.5 \\
26.5(15-42)\end{array}$ & $\begin{array}{l}26.0 \pm 6.0 \\
26(15-37)\end{array}$ & $\begin{array}{l}27.5 \pm 6.2 \\
29(15-40)\end{array}$ & 0.1296 \\
\hline BMI $\left(\mathrm{kg} / \mathrm{m}^{2}\right)$ & $\begin{array}{l}21.9 \pm 1.9 \\
22(17-24.6)\end{array}$ & $\begin{array}{l}26.9 \pm 1.9 \\
27(20-29.4)\end{array}$ & $\begin{array}{l}37.7 \pm 5.9 \\
37(30-54.4)\end{array}$ & $<0.0001$ \\
\hline Weight $(\mathrm{kg})$ & $\begin{array}{l}60.76 \pm 6.7 \\
61.5(43-75)\end{array}$ & $\begin{array}{l}76.1 \pm 7.6 \\
77.1(59-95)\end{array}$ & $\begin{array}{l}105.5 \pm 18.9 \\
102.1(62-150)\end{array}$ & $<0.0001$ \\
\hline Waist $(\mathrm{cm})$ & $\begin{array}{l}73.0 \pm 7 \\
74(55-92)\end{array}$ & $\begin{array}{l}89 \pm 11 \\
90(69-114)\end{array}$ & $\begin{array}{l}110.3 \pm 15.0 \\
109(80-163)\end{array}$ & $<0.0001$ \\
\hline Systolic blood pressure $(\mathrm{mmHg})$ & $\begin{array}{l}119 \pm 9.5 \\
117(100-138)\end{array}$ & $\begin{array}{l}124 \pm 14 \\
123(95-160)\end{array}$ & $\begin{array}{l}127.5 \pm 13.54 \\
125(100-172)\end{array}$ & $<0.0001$ \\
\hline HOMA-IR (mU mM/l) & $\begin{array}{l}1.3 \pm 1.1 \\
1.1(0.4-5.3)\end{array}$ & $\begin{array}{l}2.3 \pm 1.3 \\
2.0(0.5-6.0)\end{array}$ & $\begin{array}{l}4.92 \pm 3.4 \\
4.0(0.2-19.6)\end{array}$ & $<0.0001$ \\
\hline QUICKI & $\begin{array}{l}0.38 \pm 0.06 \\
0.38(0.04-0.46)\end{array}$ & $\begin{array}{l}0.35 \pm 0.04 \\
0.34(0.30-0.44)\end{array}$ & $\begin{array}{l}0.32 \pm 0.03 \\
0.31(0.26-0.5)\end{array}$ & $<0.0001$ \\
\hline Matsuda index & $\begin{array}{l}10.2 \pm 5.3 \\
8.9(1.7-26.3)\end{array}$ & $\begin{array}{l}6.2 \pm 4.2 \\
5.5(1.8-22.6)\end{array}$ & $\begin{array}{l}3.4 \pm 2.6 \\
2.6(0.6-17.6)\end{array}$ & $<0.0001$ \\
\hline AUC-insulin & $\begin{array}{l}144.5 \pm 82 \\
115.5(41-457)\end{array}$ & $\begin{array}{l}176.8 \pm 81.8 \\
151.0(57-423)\end{array}$ & $\begin{array}{l}309.8 \pm 167.2 \\
268.0(81-815)\end{array}$ & $<0.0001$ \\
\hline HOMA-ß (\%) & $\begin{array}{l}99.4 \pm 68.7 \\
82(22-294)\end{array}$ & $\begin{array}{l}153 \pm 85.1 \\
121(58-375)\end{array}$ & $\begin{array}{l}247.8 \pm 158.4 \\
218(9-1014)\end{array}$ & $<0.0001$ \\
\hline $\mathrm{CHOL}(\mathrm{mmol} / \mathrm{l})$ & $\begin{array}{l}183.9 \pm 35.8 \\
176(111-285)\end{array}$ & $\begin{array}{l}203 \pm 46.1 \\
195(138-314)\end{array}$ & $\begin{array}{l}193.7 \pm 32.0 \\
192(126-262)\end{array}$ & 0.0342 \\
\hline $\mathrm{HDL}(\mathrm{mmol} / \mathrm{l})$ & $\begin{array}{l}64.2 \pm 13.8 \\
63(39-109)\end{array}$ & $\begin{array}{l}58.6 \pm 12.1 \\
56(38-81)\end{array}$ & $\begin{array}{l}48.8 \pm 11.2 \\
46(30-85)\end{array}$ & $<0.0001$ \\
\hline $\mathrm{LDL}(\mathrm{mmol} / \mathrm{l})$ & $\begin{array}{l}94.9 \pm 28.22 \\
90(26-177)\end{array}$ & $\begin{array}{l}115.8 \pm 35.5 \\
101(64-201)\end{array}$ & $\begin{array}{l}117.1 \pm 35.7 \\
116(35-187)\end{array}$ & $<0.0001$ \\
\hline $\mathrm{TG}(\mathrm{mmol} / \mathrm{l})$ & $\begin{array}{l}82.5 \pm 50 \\
72(38-367)\end{array}$ & $\begin{array}{l}111.9 \pm 85.5 \\
89(36-474)\end{array}$ & $\begin{array}{l}143.1 \pm 71.7 \\
129(44-404)\end{array}$ & $<0.0001$ \\
\hline Fasting glucose (mg/dl) & $\begin{array}{l}85.7 \pm 7.6 \\
85(64-107)\end{array}$ & $\begin{array}{l}88.6 \pm 9.4 \\
86(76-113)\end{array}$ & $\begin{array}{l}94.7 \pm 12.9 \\
93(74-158)\end{array}$ & $<0.0001$ \\
\hline $\mathrm{HbA1c}(\%)$ & $\begin{array}{l}5.0 \pm 0.3 \\
5.0(4.5-6.3)\end{array}$ & $\begin{array}{l}5.3 \pm 0.7 \\
5.2(4.7-8.2)\end{array}$ & $\begin{array}{l}5.3 \pm 0.5 \\
5.2(4.6-8.8)\end{array}$ & 0.037 \\
\hline RBP4 (mg/l) & $\begin{array}{l}25.8 \pm 9.6 \\
23.9(6.3-46.6)\end{array}$ & $\begin{array}{l}28.8 \pm 11.2 \\
27.3(18.1-64.6)\end{array}$ & $\begin{array}{l}29.7 \pm 10.4 \\
27.8(12.3-73.5)\end{array}$ & 0.0291 \\
\hline
\end{tabular}

Data are given as mean \pm s.D., and as median and range. NS, not significant. Statistical analysis by ANOVA or Kruskal-Wallis test as appropriate. TG, triglycerides; CHOL, total cholesterol; HDL, high-density lipoprotein; LDL, low-density lipoprotein; RBP4, retinol-binding protein 4.

RBP4 levels might contribute to impaired insulinstimulated glucose uptake in muscle and elevated hepatic glucose production, both characteristics of T2DM. In our PCOS cohort, RBP4 levels increased with BMI. In addition, RBP4 levels correlated with waist circumference and body fat but not with parameters of insulin resistance. Our data are in accordance with study results from Janke and colleagues, who did not observe a relationship between the HOMA index and adipose RBP4 expression, or with circulating RBP4 levels (27). Interestingly, in obese women, a 5\% weight loss improved the HOMA index by $20 \%$, but this change was not associated with a significant change in RBP4 levels (28). In three populations with different metabolic conditions, RBP4 levels were correlated not only with total obesity, BMI, and abdominal obesity but, in contrast to other studies, also with parameters of insulin metabolism determined by euglycemic clamp techniques (29). Furthermore, Graham et al. showed that exercise training led to a reduction in RBP4 levels only in those subjects who showed improved insulin resistance. In morbidly obese patients, RBP4 levels
Table 2 Correlation of retinol-binding protein 4 levels with metabolic parameters in women with polycystic ovary syndrome $(n=200)$.

\begin{tabular}{lcc}
\hline & \multicolumn{2}{c}{ Retinol-binding protein $\mathbf{4}$} \\
\cline { 2 - 3 } Variable & $r$ & $P$ \\
\hline Body weight & 0.1827 & 0.0098 \\
BMI & 0.1519 & 0.0322 \\
Body fat & 0.1444 & 0.0474 \\
Waist circumference & 0.1658 & 0.0209 \\
HOMA-IR & 0.0854 & 0.2399 \\
QUICKI & -0.0866 & 0.2338 \\
Matsuda index & -0.0644 & 0.3759 \\
AUC-insulin & 0.0275 & 0.7050 \\
HOMA- $\beta$ & 0.0608 & 0.4032 \\
Fasting glucose & 0.1443 & 0.0476 \\
AUC-glucose & 0.1565 & 0.0311 \\
TG & 0.2251 & 0.0014 \\
CHOL & 0.1058 & 0.1368 \\
HDL cholesterol & -0.1019 & 0.1521 \\
LDL cholesterol & 0.0108 & 0.1289 \\
\hline
\end{tabular}

Data are given as Spearman correlation coefficients. TG, triglycerides; CHOL, total cholesterol; HDL, high-density lipoprotein; LDL, low-density lipoprotein; AUC, area under the curve. 
Table 3 Metabolic characteristics of lean polycystic ovary syndrome (PCOS) women and lean healthy controls.

\begin{tabular}{|c|c|c|c|}
\hline & $\operatorname{Pcos}(n=58)$ & Controls $(n=64)$ & $\boldsymbol{P}$ \\
\hline Age (years) & $\begin{array}{l}25.9 \pm 5.5 \\
26.5(15-42)\end{array}$ & $\begin{array}{l}26.1 \pm 5.1 \\
25(17-42)\end{array}$ & 0.3752 \\
\hline BMI $\left(\mathrm{kg} / \mathrm{m}^{2}\right)$ & $\begin{array}{l}21.9 \pm 1.9 \\
22(17-24.6)\end{array}$ & $\begin{array}{l}21.8 \pm 1.8 \\
22(18.8-24.8)\end{array}$ & 0.1140 \\
\hline Weight (kg) & $\begin{array}{l}60.76 \pm 6.7 \\
61.5(43-75)\end{array}$ & $\begin{array}{l}61.4 \pm 7.3 \\
60.5(48-77)\end{array}$ & 0.5872 \\
\hline Waist (cm) & $\begin{array}{l}73.0 \pm 7 \\
74(55-92)\end{array}$ & $\begin{array}{l}75.4 \pm 5.7 \\
75(61-94)\end{array}$ & 0.0701 \\
\hline Body fat (\%) & $\begin{array}{l}28.2 \pm 3.3 \\
28.2(21.8-34.6)\end{array}$ & $\begin{array}{l}27.5 \pm 2.7 \\
27(22-34.4)\end{array}$ & 0.0558 \\
\hline HOMA-IR (mU mM/l) & $\begin{array}{l}1.3 \pm 1.1 \\
1.1(0.4-5.3)\end{array}$ & $\begin{array}{l}1.5 \pm 0.7 \\
1.4(0.4-3.2)\end{array}$ & 0.0620 \\
\hline $\mathrm{HDL}(\mathrm{mmol} / \mathrm{l})$ & $\begin{array}{l}64.2 \pm 13.8 \\
63(39-109)\end{array}$ & $\begin{array}{l}70.9 \pm 15.9 \\
69(39-105)\end{array}$ & 0.0080 \\
\hline $\mathrm{LDL}(\mathrm{mmol} / \mathrm{l})$ & $\begin{array}{l}94.9 \pm 28.22 \\
90(26-177)\end{array}$ & $\begin{array}{l}103.9 \pm 26.7 \\
103.5(50-185)\end{array}$ & 0.0536 \\
\hline $\mathrm{TG}(\mathrm{mmol} / \mathrm{l})$ & $\begin{array}{l}82.3 \pm 50.4 \\
74(38-367)\end{array}$ & $\begin{array}{l}95.6 \pm 36.3 \\
92.5(42-197)\end{array}$ & 0.0107 \\
\hline Fasting glucose (mg/dl) & $\begin{array}{l}85.7 \pm 7.6 \\
85(64-107)\end{array}$ & $\begin{array}{l}83.9 \pm 6.8 \\
84(63-102)\end{array}$ & 0.2171 \\
\hline $\mathrm{HbA1c}(\%)$ & $\begin{array}{l}5.0 \pm 0.3 \\
5.0(4.5-6.3)\end{array}$ & $\begin{array}{l}4.8 \pm 0.3 \\
4.9(4.2-5.7)\end{array}$ & 0.0146 \\
\hline RBP4 (mg/l) & $\begin{array}{l}25.8 \pm 9.6 \\
23.9(6.1-46.6)\end{array}$ & $\begin{array}{l}25.7 \pm 5.6 \\
24.4(14.1-39.3)\end{array}$ & 0.6317 \\
\hline Testosterone (nmol/l) & $\begin{array}{l}2.6 \pm 0.8 \\
2.5(1.3-4.6)\end{array}$ & $\begin{array}{l}1.4 \pm 0.4 \\
1.4(0.6-2.2)\end{array}$ & $<0.0001$ \\
\hline FAI & $\begin{array}{l}5.8 \pm 4.9 \\
4.2(0.8-24.5)\end{array}$ & $\begin{array}{l}1.2 \pm 0.9 \\
1.0(0.7-2.1)\end{array}$ & $<0.0001$ \\
\hline Hirsutism score & $\begin{array}{l}6.8 \pm 5.2 \\
6(0-21)\end{array}$ & $\begin{array}{l}1.4 \pm 1.7 \\
1(0-5)\end{array}$ & $<0.0001$ \\
\hline
\end{tabular}

Data are given as mean \pm s.D. and as median and range. TG, triglycerides; CHOL, total cholesterol; HDL, high-density lipoprotein; LDL, low-density lipoprotein; RBP4, retinol-binding protein 4; FAl, free androgen index.

correlated with BMI (15), consistent with our findings in PCOS women. Haider and co-workers did not find a correlation between RBP4 levels and parameters of insulin resistance, suggesting that differences found between the studies might also be due to sample size, a selection bias, or the choice of methodology for the evaluation of insulin resistance. One can speculate that the detection of RBP4-mediated changes in insulin sensitivity may require glucose clamp techniques as the most accurate measurement of insulin sensitivity. In contrast to our data, Cho et al. (30) did not find a correlation between RBP4 levels and body fat. Again, this could be a sampling bias, as they performed body fat measurement using the less sensitive bioimpedance method and not by the more accurate DEXA, as we did.

In German PCOS women, RBP4 levels did not correlate with biochemical or clinical parameters of hyperandrogenism. In addition, no differences in RBP4 levels between lean PCOS women and BMI-matched controls were found. Therefore, RBP4 levels do not appear to be influenced by PCOS per se.

The RBP4 gene is located on chromosome 10q24 in humans near a region linked to levels of both 20-year mean and current fasting glucose in European Caucasians (31). This region contains at least one interesting candidate gene, hexokinase 1 , the gene encoding a key enzyme in the initial step of glucose metabolism. Furthermore, increased serum RBP4 levels are known to stimulate hepatic gluconeogenesis through stimulation of phosphoenolpyruvate carboxykinase (13). Study data from Cho and colleagues (30) demonstrated elevated RBP4 levels in patients with IGT and T2DM. In addition, plasma glucose levels increased with plasma RBP4 quartiles. Similar results were found in our German PCOS population. In keeping with this, in German PCOS women, a significant correlation between RBP4 levels and fasting glucose as well as AUC-glucose was found. A positive family history of T2DM was not associated with higher RBP4 levels in German PCOS subjects.

Further studies are needed to confirm these findings and investigate whether RBP4 levels can predict a future development of type 2 diabetes in PCOS women.

\section{References}

1 Hahn S, Tan S, Elsenbruch S, Quadbeck B, Herrmann BL, Mann K \& Janssen OE. Clinical and biochemical characterization of women with polycystic ovary syndrome in North Rhine-Westphalia. Hormone and Metabolic Research $200537438-444$. 
2 Holte J, Gennarelli G, Berne C, Bergh T \& Lithell H. Elevated ambulatory day-time blood pressure in women with polycystic ovary syndrome: a sign of a pre-hypertensive state? Human Reproduction 199611 23-28.

3 Dunaif A, Segal KR, Futterweit W \& Dobrjansky A. Profound peripheral insulin resistance, independent of obesity, in polycystic ovary syndrome. Diabetes 198938 1165-1174.

4 Legro RS, Kunselman AR, Dodson WC \& Dunaif A. Prevalence and predictors of risk for type 2 diabetes mellitus and impaired glucose tolerance in polycystic ovary syndrome: a prospective, controlled study in 254 affected women. Journal of Clinical Endocrinology and Metabolism 199984 165-169.

5 Ehrmann DA, Barnes RB, Rosenfield RL, Cavaghan MK \& Imperial J. Prevalence of impaired glucose tolerance and diabetes in women with polycystic ovary syndrome. Diabetes Care 199922 141-146.

6 Pelusi B, Gambineri A \& Pasquali R. Type 2 diabetes and the polycystic ovary syndrome. Minerva Ginecologica 200456 41-51.

7 Aronne LJ \& Segal KR. Adiposity and fat distribution outcome measures: assessment and clinical implications. Obesity Research 200210 (Suppl 1) 14S-21S.

8 Yildiz BO, Yarali H, Oguz H \& Bayraktar M. Glucose intolerance, insulin resistance, and hyperandrogenemia in first degree relatives of women with polycystic ovary syndrome. Journal of Clinical Endocrinology and Metabolism 200388 2031-2036.

9 Roldan B, San Millan JL \& Escobar-Morreale HF. Genetic basis of metabolic abnormalities in polycystic ovary syndrome: implications for therapy. American Journal of Pharmacogenomics 20044 93-107.

10 Urbanek M, Legro RS, Driscoll DA, Azziz R, Ehrmann DA, Norman RJ, Strauss JF, III, Spielman RS \& Dunaif A. Thirty-seven candidate genes for polycystic ovary syndrome: strongest evidence for linkage is with follistatin. PNAS $1999968573-8578$.

11 Carmina E, Orio F, Palomba S, Longo RA, Cascella T, Colao A, Lombardi G, Rini GB \& Lobo RA. Endothelial dysfunction in PCOS: role of obesity and adipose hormones. American Journal of Medicine $2006119356 . e 1-356 . e 6$.

12 Orio F, Jr, Palomba S, Cascella T, Milan G, Mioni R, Pagano C, Zullo F, Colao A, Lombardi G \& Vettor R. Adiponectin levels in women with polycystic ovary syndrome. Journal of Clinical Endocrinology and Metabolism 2003 88 2619-2623.

13 Yang Q, Graham TE, Mody N, Preitner F, Peroni OD, Zabolotny JM, Kotani K, Quadro L \& Kahn BB. Serum retinol binding protein 4 contributes to insulin resistance in obesity and type 2 diabetes. Nature 2005436 356-362.

14 Haider DG, Schindler K, Mittermayer F, Muller M, Nowotny P, Rieger A, Luger A, Ludvik B \& Wolzt M. Effect of rosiglitazone on visfatin and retinol-binding protein-4 plasma concentrations in HIV-positive patients. Clinical Pharmacology and Therapeutics 2007 81 580-585.

15 Haider DG, Schindler K, Prager G, Bohdjalian A, Luger A, Wolzt M \& Ludvik B. Serum retinol-binding protein- 4 is reduced after weight loss in morbidly obese subjects. Journal of Clinical Endocrinology and Metabolism 200692 1168-1171.

16 Munkhtulga L, Nakayama K, Utsumi N, Yanagisawa Y, Gotoh T, Omi T, Kumada M, Erdenebulgan B, Zolzaya K, Lkhagvasuren T \& Iwamoto S. Identification of a regulatory SNP in the retinol binding protein 4 gene associated with type 2 diabetes in Mongolia. Human Genetics 2007120 879-888.
17 Craig RL, Chu WS \& Elbein SC. Retinol binding protein 4 as a candidate gene for type 2 diabetes and prediabetic intermediate traits. Molecular Genetics and Metabolism $200690338-344$.

18 Ludwig E. Classification of the types of androgenetic alopecia (common baldness) occurring in the female sex. British Journal of Dermatology $197797247-254$.

19 ESHRE/ASRM. Revised 2003 consensus on diagnostic criteria and long-term health risks related to polycystic ovary syndrome. Fertility and Sterility 200481 19-25.

20 Matthews DR, Hosker JP, Rudenski AS, Naylor BA, Treacher DF \& Turner RC. Homeostasis model assessment: insulin resistance and beta-cell function from fasting plasma glucose and insulin concentrations in man. Diabetologia 1985 28 412-419.

21 Katz A, Nambi SS, Mather K, Baron AD, Follmann DA, Sullivan G \& Quon MJ. Quantitative insulin sensitivity check index: a simple, accurate method for assessing insulin sensitivity in humans. Journal of Clinical Endocrinology and Metabolism $2000 \mathbf{8 5}$ 2402-2410.

22 Matsuda M \& DeFronzo RA. Insulin sensitivity indices obtained from oral glucose tolerance testing: comparison with the euglycemic insulin clamp. Diabetes Care $1999221462-1470$.

23 Goodarzi MO, Erickson S, Port SC, Jennrich RI \& Korenman SG. Relative impact of insulin resistance and obesity on cardiovascular risk factors in polycystic ovary syndrome. Metabolism $2003 \mathbf{5 2}$ 713-719.

24 Legro RS, Gnatuk CL, Kunselman AR \& Dunaif A. Changes in glucose tolerance over time in women with polycystic ovary syndrome: a Controlled Study. Journal of Clinical Endocrinology and Metabolism $2005903236-3242$.

25 Panidis D, Rousso D, Kourtis A, Tsimas V, Papathanasiou K \& Makedos G. Serum leptin levels in normal-weight and overweight women with polycystic ovary syndrome. Clinical and Experimental Obstetrics \& Gynecology 200330 207-210.

26 Orio F, Jr, Lucidi P, Palomba S, Tauchmanova L, Cascella T, Russo T, Zullo F, Colao A, Lombardi G \& De Feo P. Circulating ghrelin concentrations in the polycystic ovary syndrome. Journal of Clinical Endocrinology and Metabolism 2003 88 942-945.

27 Janke J, Engeli S, Boschmann M, Adams F, Bohnke J, Luft FC, Sharma AM \& Jordan J. Retinol-binding protein 4 in human obesity. Diabetes $2006 \mathbf{5 5} 2805-2810$.

28 Engeli S, Bohnke J, Gorzelniak K, Janke J, Schling P, Bader M, Luft FC \& Sharma AM. Weight loss and the renin-angiotensinaldosterone system. Hypertension $200545356-362$.

29 Graham TE, Yang Q, Bluher M, Hammarstedt A, Ciaraldi TP, Henry RR, Wason CJ, Oberbach A, Jansson PA, Smith U \& Kahn BB. Retinol-binding protein 4 and insulin resistance in lean, obese, and diabetic subjects. New England Journal of Medicine 2006 $3542552-2563$.

30 Cho YM, Youn BS, Lee H, Lee N, Min SS, Kwak SH, Lee HK \& Park KS. Plasma retinol-binding protein-4 concentrations are elevated in human subjects with impaired glucose tolerance and type 2 diabetes. Diabetes Care 200629 2457-2461.

31 Meigs JB, Panhuysen CI, Myers RH, Wilson PW \& Cupples LA. A genome-wide scan for loci linked to plasma levels of glucose and $\mathrm{HbA}(1 \mathrm{c})$ in a community-based sample of Caucasian pedigrees: the Framingham Offspring Study. Diabetes 200251 833-840.

Received 7 March 2007

Accepted 21 May 2007 